\title{
Relationships between Chronic Diseases and Depression among Middle- aged and Elderly People in China: A Prospective Study from CHARLS*
}

\author{
Chun-hong JIANG ${ }^{1}$, Feng ZHU², Ting-ting QIN"\# \\ ${ }^{1}$ School of Management, Hubei University of Education, Wuhan 430205, China \\ ${ }^{2}$ Department of Biliary-Pancreatic Surgery, Tongji Hospital, Tongji Medical College, Huazhong University of Science and \\ Technology, Wuhan 430030, China
}

(C) The Author(s) 2020

\begin{abstract}
Summary: Given the rapid increase in the prevalence of chronic diseases in aging populations, this prospective study including 17707 adults aged $\geq 45$ years from China Health and Retirement Longitudinal Study was used to estimate the associations between chronic disease, multimorbidity, and depression among middle-aged and elderly adults in China, and explore the mediating factors. Depressive symptoms were assessed using the 10-item Centre for Epidemiological Studies Depression Scale (CES-D-10) questionnaire. Twelve chronic physical conditions, including hypertension, diabetes, dyslipidemia, cancer, chronic lung disease, liver disease, heart failure, stroke, kidney disease, arthritis or rheumatism, asthma, digestive disease were assessed. The prevalence rates for physical multimorbidity and depression (CES-D-10 $\geq 10$ ) were $43.23 \%$ and $36.62 \%$, respectively. Through multivariable logistic models and generalized estimating equation (GEE) models, we found all 12 chronic physical conditions, and multimorbidity were significantly associated with depression. Both mobility problems and chronic pain explained more than $30 \%$ of the association for all chronic conditions, with particularly high percentages for stroke $(51.56 \%)$ and cancer $(51.06 \%)$ in mobility problems and cancer $(53.35 \%)$ in chronic pain. Limited activities of daily living (ADL) explained $34.60 \%$ of the stroke-cancer relationship, while sleep problems explained between $10.15 \%$ (stroke) and $14.89 \%$ (chronic lung disease) of the association. Individuals with chronic diseases or multimorbidity are significantly more likely to be depressed. Functional symptoms involving limitations of ADL and mobility difficulties mediated much of the association between chronic diseases and incident depression. These symptoms could be targeted for interventions to ameliorate the incidence of depression among individuals with chronic conditions.
\end{abstract}

Key words: chronic disease; multimorbidity; depression; functional symptoms; mediation effect

China has the largest national population of any country at almost 1.4 billion, and is becoming a rapidly aging nation as life expectancy increases. Predictions indicate that there will be a large increase in China's elderly population by 2050 , with up to 400 million people aged over 65 , and 500 million people aged over $80^{[1]}$. Age-related health problems represent a core issue in the aging process ${ }^{[2]}$, with chronic non-communicable diseases and mental health disorders being the two major types. Chronic non-communicable diseases have received substantial research attention, with the highest disease burden of any illness category in China ${ }^{[3]}$. In

Chun-hong JIANG, E-mail: 953345080@qq.com \#Corresponding author, E-mail: qintingting77@163.com ${ }^{*}$ This study was supported by the MOE (Ministry of Education in China) Liberal Arts and Social Sciences Youth Foundation (No. 16YJC630047). contrast, despite their high prevalence ${ }^{[4]}$, mental health disorders including depression are often neglected and underdiagnosed due to the stigma of mental illness in some areas of $\mathrm{China}^{[5]}$.

Over the past several decades, high prevalence of depression has been reported among patients with a range of chronic illnesses, including $17 \%-27 \%$ of patients with cardiovascular disease ${ }^{[6]}, 11 \%-31 \%$ of patients with diabetes ${ }^{[7]}$ and $10 \%-24 \%$ of patients with $\operatorname{arthriti}^{[8]}$. Moreover, a higher prevalence of depression was reported in people with at least one chronic physical condition $(9.3 \%-23 \%)$ compared with those with none $(3.2 \%)^{[9]}$. Research interest in the relationship between chronic illness and depression has increased in recent years. The World Health Organization's (WHO) Global Burden of Disease Study reported that people with chronic illnesses were significantly more likely to suffer from depression, and that the 
comorbidity between chronic diseases and depression is common ${ }^{[10]}$. It is well established that depression is associated with several chronic illnesses ${ }^{[11]}$, including diabetes $^{[12-14]}$, hypertension ${ }^{[15]}$, arthritis ${ }^{[16]}$, chronic kidney disease ${ }^{[17]}$, chronic lung disease ${ }^{[18]}$, cancer ${ }^{[19]}$, asthma $^{[20]}$, and stroke ${ }^{[21]}$. Furthermore, depression is reported to be two or three times more likely in people with multimorbidity (characterized by the presence of two or more chronic physical conditions) compared to people without multimorbidity or those who have no chronic illness ${ }^{[22]}$, which has now been another public concern and has worse effect on depression. The assessment and treatment of chronic disease can be confused by depression, and vice versa. Thus, it is important to investigate how those chronic diseases differentially affect depression prospectively.

Functional health has long been recognized as a major predictor of depression. Previous study found that the chronic illness was not associated with depression unless the illness and functional discomforts occurred simultaneously ${ }^{[23]}$. Depression may operate principally through functional health with an indirect bearing on chronic illness. Functional health might be a mediator in the association between physical illness and depression by restricting social activities, leading to poor sleep, mobility difficulties, as well as chronic body pain ${ }^{[24,25]}$. Functional health was common feelings in people with chronic illness, especially in the elderly. While, there is a paucity of information on functional health [mobility difficulties, activities of daily living (ADL), chronic pain, and sleep problems] that might influence the relationship between chronic illness/multimorbidity and depression for few studies focus on the association of somatic symptomatology and chronic diseases as well as the depression.

Thus, we aimed to assess the association between chronic disease/multimorbidity and depression among Chinese adults aged $\geq 45$ years, focusing on the following questions: 1) is there a significantly increased risk of depression among people with chronic diseases or multimorbidity compared with those with no functional health? 2) does the risk of depression significantly increase with the number of chronic diseases? 3) do any of these risks or relationships differ significantly across age and gender groups? and 4) does functional health mediate the relationships between depression and chronic conditions?

\section{MATERIALS AND METHODS}

\subsection{Sample}

Data were collected from the China Health and Retirement Longitudinal Study (CHARLS), an ongoing nationally representative cohort study involving a longitudinal survey of people aged 45 and over and their partners (regardless of age) in China. CHARLS is a public dataset supported by Peking University, and shares the same basic guidelines as the Health and Retirement Study and related aging surveys such as the Indonesia Family Life Panel and the Korean Longitudinal Study of Aging. A baseline survey was conducted from 2011 to 2012, and individuals were followed up every 2 years. To date, the survey data of the national baseline survey (visit I, 2011y), the first follow-up survey (visit II, 2013y), and the second follow-up survey (visit III, 2015y) have been released, and are available at the study website (http://charls. ccer.edu.cn/zh-CN). Informed consent was obtained from all participants. The biomedical ethics committee of Beijing University approved the study, and detailed descriptions of the survey design and procedures were reported in the original study documentation ${ }^{[26]}$.

A total of 17707 individuals took part in the baseline survey. Of these, 14978 were re-investigated at visit II (2013y) and 10291 at visit III (2015y). The inclusion criteria for this study were as follows: 1) aged $\geq 45$ years; 2 ) no severe cognitive impairment (to ensure accurate measurement of self-reported information of interest); 3) complete information about age, gender, chronic disease and depression assessment; and 4) not taking any antidepressants. A total of 14392 respondents fulfilled the inclusion criteria and were included in the cross-sectional analysis. Because most information was obtained via specific questionnaires and physical disabilities could strongly influence people's daily activity, we excluded respondents with the following conditions: physical disabilities; brain damage/mental retardation; vision problems; hearing problems; and speech impediment. Thus, 9104 participants were included in the final analysis. The study flow is shown in fig. 1.

\subsection{Chronic Disease and Comorbidities}

Chronic diseases were defined at the baseline survey. Hypertension was defined as mean systolic blood pressure $\geq 140 \mathrm{mmHg}$ and/or mean diastolic blood pressure $\geq 90 \mathrm{mmHg}$, and/or current use of antihypertensive drugs, or any self-reported history of physician-diagnosed hypertension ${ }^{[27]}$. Dyslipidemia was defined as total cholesterol $>6.2 \mathrm{mmol} / \mathrm{L}$, triglycerides $\geq 2.3 \mathrm{mmol} / \mathrm{L}$, LDL-C $\geq 4.1 \mathrm{mmol} / \mathrm{L}$, HDL-C $<1.0 \mathrm{mmol} / \mathrm{L}$ in men or HDL-C $<1.3 \mathrm{mmol} / \mathrm{L}$ in women, or taking any treatment to lower blood lipid levels, or having any self-reported history of physiciandiagnosed dyslipidemia ${ }^{[28]}$. Diabetes was defined as fasting plasma glucose $\geq 7.0 \mathrm{mmol} / \mathrm{L}$ and/or $\mathrm{HbA} 1 \mathrm{c} \geq$ $6.2 \mathrm{mmol} / \mathrm{L}$, or current use of any treatment to control blood sugar, regardless of fasting plasma glucose levels, or any self-reported history of physiciandiagnosed diabetes ${ }^{[29]}$. Other chronic diseases, such as chronic lung disease (e.g., chronic bronchitis or emphysema, excluding tumors or cancers); liver disease (except fatty liver, tumors, or cancers); heart attack 


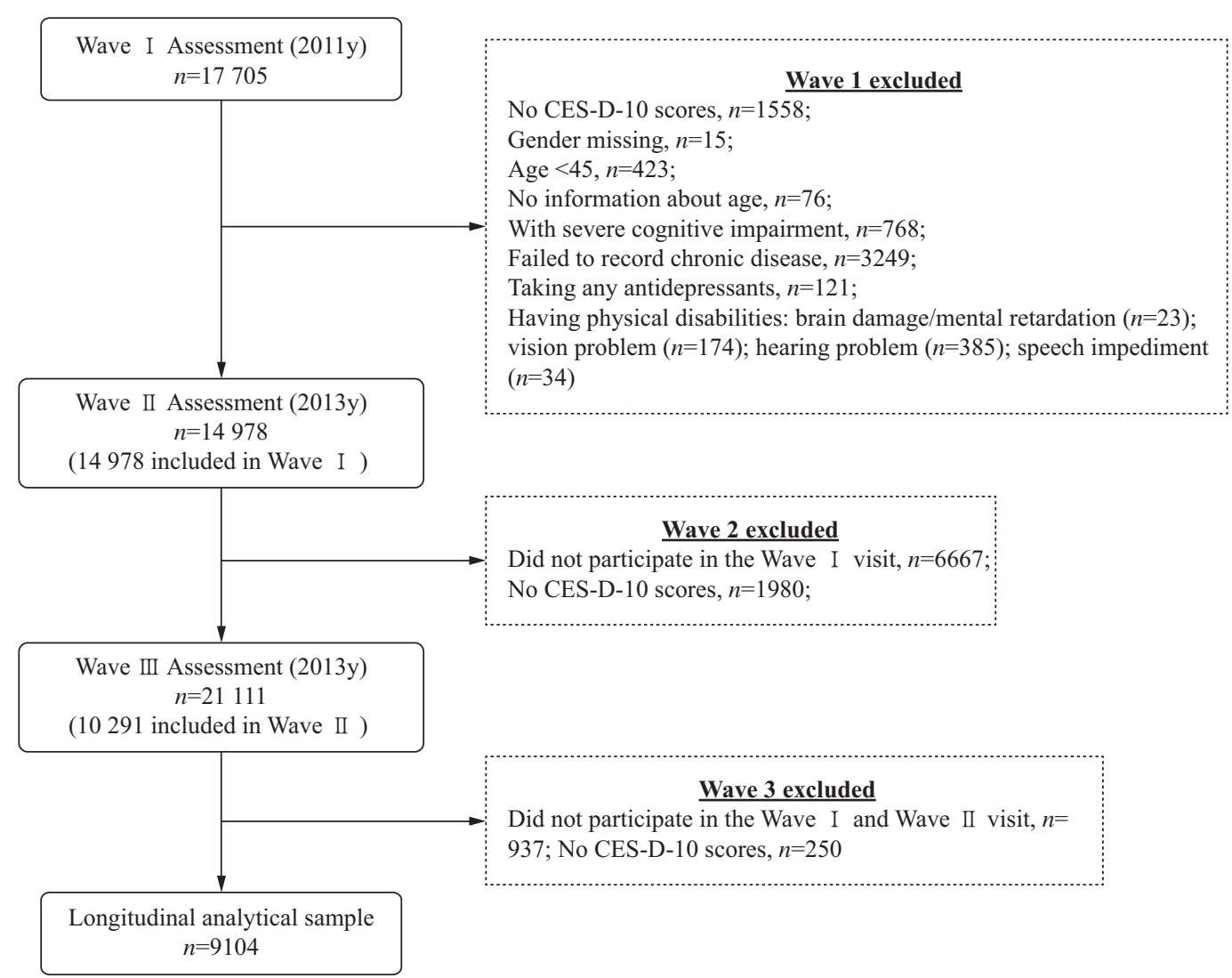

Fig. 1 The study flow

CES-D-10: Center for Epidemiologic Studies Depression Scale

(including coronary heart disease, angina, congestive heart failure, or other heart problems); stroke; kidney disease (except for tumor or cancer); digestive diseases (except for tumor or cancer); arthritis or rheumatism, and asthma, were identified according to self-reported physician diagnosis or taking any treatment for related diseases or complications. These diseases were chosen because of their permanent features, their nonreversible pathological causes, or the requirement of rehabilitation or a long period of car $\mathrm{e}^{[30]}$. A previous study reported that respondents' self-report data regarding chronic disease had highly satisfactory agreement with information from their general practitioners, and accuracy was not found to be influenced by depression ${ }^{[31]}$. Respondents reporting negative responses to all the measured or self-reported diagnoses for the aforementioned diseases were selected as the healthy control group. Multimorbidity was defined as having two or more of any aforementioned chronic diseases. All blood samples involved in the diagnosis were collected during the baseline follow-up survey, and the details were published previously ${ }^{[32]}$.

\subsection{Depression}

Depressive symptoms were measured using the Center for Epidemiologic Studies Depression Scale (CES-D-10) in the CHARLS, which has been validated with elderly respondents in $\mathrm{China}^{[33]}$. The response scale for the CES-D-10 includes 10 questions regarding participants experience during the past week: feeling bothered, having trouble in concentrating, feeling depressed, feeling as though everything was effortful, feeling hopeful, feeling fearful, having restless sleep, feeling happy, feeling lonely, and having difficulty in getting going. The details were published in a previous study $^{[32]}$. Total CES-D-10 scores range from 0 to 30 , with higher scores indicating more serious depressive symptoms. We used a cut-off score of $\geq 10$ to distinguish participants with depression from those who were relatively free of depression ${ }^{[33]}$. The CES-D-10 used in this study exhibited good internal consistency, with $\alpha$ $=0.793$ at baseline investigation (2011y), $\alpha=0.787$ at follow-up investigation (2013y), and $\alpha=0.779$ at the second follow-up investigation (2015y).

\subsection{Functional Health and Covariates}

Functional health was evaluated using 50 healthrelated questions pertaining to four health domains: mobility, ADL, chronic pain, and night-time sleeping. Mobility difficulties were defined as difficulty in relevant abilities, including running or jogging, getting up from a chair after sitting for a long period, climbing several flights of stairs without resting, stooping, kneeling, or crouching, and carrying weights over 5 $\mathrm{kg}$. ADL ability was measured by asking participants whether they had any difficulties taking a bath, eating, getting in and out of bed, dressing, using the toilet, defecating, doing housework, cooking, making 
phone calls, taking medicine, shopping and managing finances due to health and memory problems during the past 3 months. The detailed evaluation methods were previously reported by Katz ${ }^{[34]}$ and Lawton ${ }^{[35]}$. If any difficulty was reported and then the reporter would be recognized as had difficulty in mobility or ADL. Chronic pain was defined as pain that persisted after healing would be expected to have taken place, or pain persisting in the absence of tissue damage ${ }^{[36]}$. Chronic pain was assessed by asking participants whether they were troubled by any such body pains. Chronic pain was recorded as positive if participants responded "yes", and negative if they responded "no". Sleep problems were defined as night-time sleeping duration of less than $6 \mathrm{~h}$. These four domains were used as initial indicators of functional health in the CHARLS dataset.

Based on previous studies, we conducted preliminary analyses for testing multiple confounders for chronic disease or depressive symptoms through standard questionnaires. These covariates included gender and age, living areas, marital status, education level, smoking status, alcohol use, body mass index (BMI, $\mathrm{kg} / \mathrm{m}^{2}$ ), abdominal adiposity, and daily activities. In addition, we considered self-reported life satisfaction and self-reported good health as potential confounders.

\subsection{Statistical Analysis}

Differences in sample characteristics by age group (45-64 years $v s . \geq 65$ years) were evaluated using Chisquared tests. Multivariable logistic regression analysis with consideration of complex survey design was applied to assess the cross-sectional association between chronic conditions or multimorbidity (exposure variables) and depression (outcome variable) while adjusting for multi-covariates. The generalized estimating equation model, which can consider time-dependent effects, was applied to explore the prospective influence of prevalent chronic diseases and the incidence of depression, where incident depression was defined as CES-D-10 score $<10$ at baseline survey, then CES-D-10 score $\geq 10$ at the following two surveys (2013y and 2015y). The logit link function was used in the GEE model, and the working covariance matrix was defined as "unstructured correlation". The results were presented as odds ratios (ORs) with 95\% confidence intervals (CIs).

Given that some functional symptoms regarding mobility difficulties, ADL, chronic pain, and night- time sleeping may be linked to chronic conditions as part of the symptomatology or the consequences of chronic conditions, we conducted mediational analysis to evaluate underlying factors that may explain the link between chronic conditions or multimorbidity and depression among the whole population. Considering that the continuous variable of depression could make full use of the information, we used the CES-D-10 scores assessed in wave I, wave II and wave III as the main outcome. A linear regression approach guided by Baron and Kenny's method was applied ${ }^{[38]}$. There were three depression assessments in the different surveys, so the GEE model was applied as the analytical model, with the working covariance matrix defined as the "unstructured correlation". In the first step, the outcome variable (CES-D-10 score) was regressed on the independent variable (separate chronic conditions as well as multimorbidity). This method indicates the total effect of the predictor on the outcome variable. In the second step, the mediator variable (mobility difficulties, limited ADL, chronic pain, and poor sleep) was regressed on the independent variable (separate chronic conditions as well as multimorbidity). The outcome variable was then regressed on the mediator variable in the third step. In the final step, the outcome variable was regressed on the mediator variable and the independent variable. The details are shown in fig. 2. The Sobel test was used to confirm the significance of the mediator effect. This method decomposed the total effect into direct and indirect effects and the mediated percentage (percentage of the main association explained by the mediator) could be calculated. Each potential mediator was included in the models separately and the models were adjusted for covariates. The sample weighting and the complex study design were taken into account in all analyses. The level of statistical significance was set at two-sided $P<0.05$. The statistical analysis was performed using SAS, 9.4 (SAS Institute, Inc., USA)

\section{RESULTS}

\subsection{Sample Characteristics}

The final analytical sample included 14392 participants aged $\geq 45$ years in the cross-sectional analysis and 9104 participants in the longitudinal

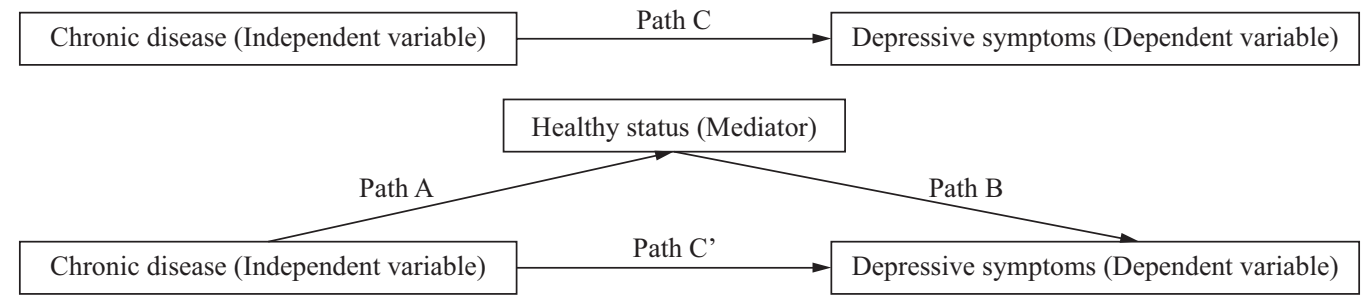

Fig. 2 The analytical framework of mediation analysis 
analysis. The median (interquartile range, IQR) age was 58 (14) years and $48.17 \%$ of participants were male. The median CES-D-10 was 7 (IQR, 3-12) and the prevalence of depression (CES-D-10 $\geq 10$ ) was $36.62 \%$. The prevalence of multimorbidity was $43.23 \%$. The detailed sample characteristics as well as the gender specific difference are presented in table 1 .

The prevalence of depressive symptoms alone, each chronic disease alone, and multimorbidity (comorbidity of two or more chronic diseases) were estimated, and stratified for age and sex separately at baseline. The prevalence of arthritis or rheumatism had the highest overall prevalence of $55.61 \%$, followed by hypertension $(49.06 \%)$ and stomach or other digestive diseases $(45.69 \%)$. In addition, the prevalence of multimorbidity was notably high, at $43.23 \%$. Since all chronic diseases except hypertension and diabetes were based on self-reported measures, the potential effects of reporting bias on prevalence estimation should not be neglected. Moreover, the stratification results indicated that the prevalence of the 12 assessed chronic diseases among elderly participants ( $\geq 65$ years) was substantially higher than that among middle-aged participants ( $\geq 45$ years $<65$ years). Except for stroke and liver disease, other chronic diseases exhibited higher prevalence among females than males. The prevalence of depressive symptoms increased in a linear fashion with an increasing number of chronic conditions ranging from $23.34 \%$ in people with no chronic conditions to $61.31 \%$ among people with three or more chronic diseases. The details of these analyses are shown in table 2 .

\subsection{Association between Chronic Diseases and Depression}

A relatively high percentage of respondents with one or more chronic diseases also exhibited depression. Participants with asthma had the highest prevalence of depression $(57.68 \%)$, while those with hypertension had the lowest prevalence (37.21\%). The prevalence of depression increased in a linear fashion with the number of chronic conditions, ranging from $23.34 \%$ in participants without any chronic conditions to $61.31 \%$ in participants with more than three chronic conditions. Furthermore, the prevalence of depression was also higher in the elderly ( $\geq 65$ years) in regarding to most chronic conditions, such as among those with stroke $(58.33 \%)$, kidney disease $(56.49 \%)$, stomach disease $(56.73 \%)$, arthritis $(55.25 \%)$, asthma (55.51\%) and multimorbidity $(50.78 \%)$, and the prevalence of depression was significantly higher among older individuals ( $\geq 65$ years). The details of these findings are shown in fig. 3 .

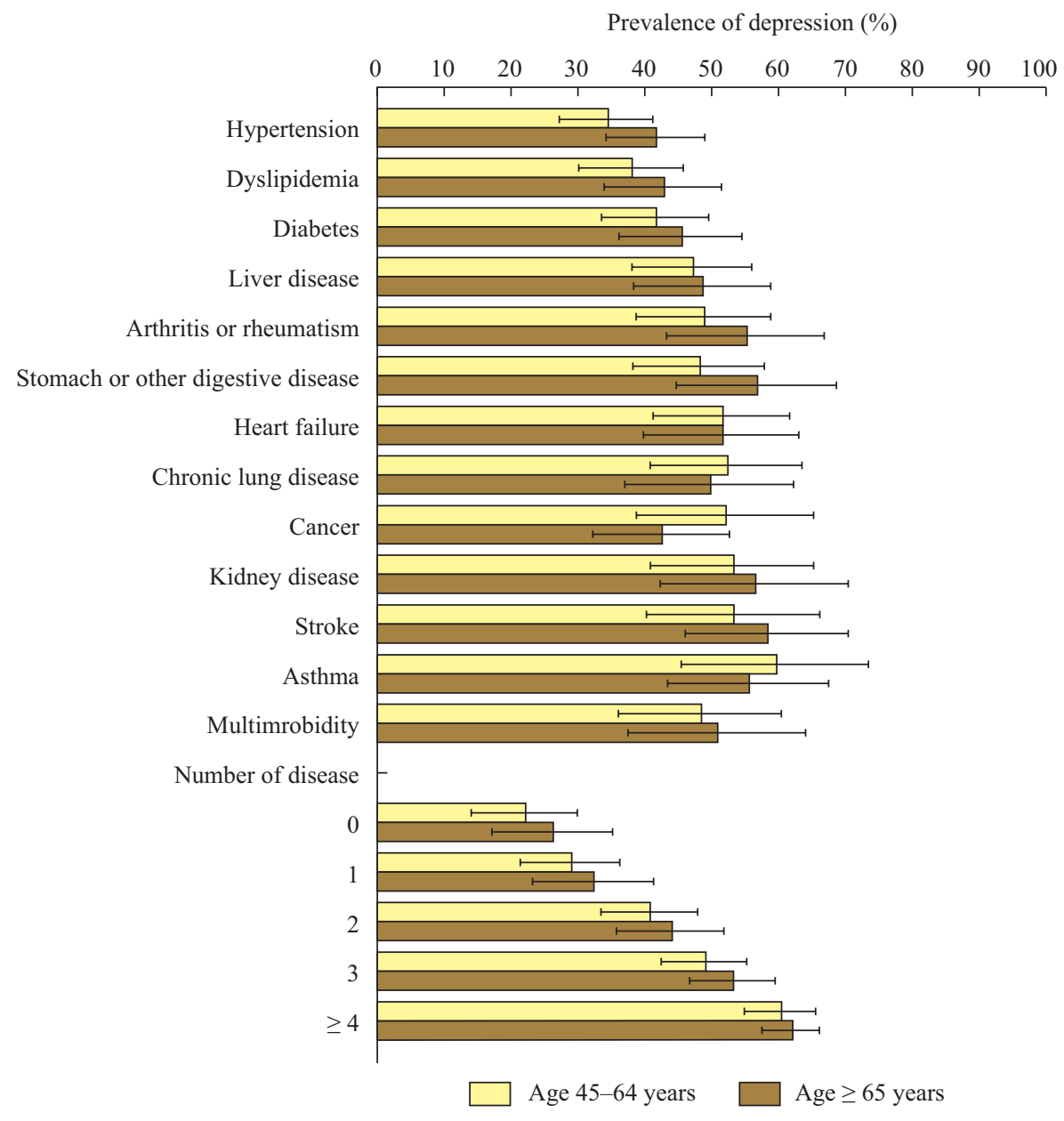

Fig. 3 Prevalence of depression 
Table 1 Sample characteristics (overall and by age group, $n=14392$ )

\begin{tabular}{|c|c|c|c|c|}
\hline \multirow{2}{*}{ Characteristic } & \multirow{2}{*}{ Total } & \multicolumn{3}{|c|}{ Age group } \\
\hline & & $45-64$ y $(n=10566)$ & $\geq 65$ y $(n=3826)$ & $P$-value \\
\hline $\begin{array}{l}\text { Age (years), mean } \pm \text { standard } \\
\text { deviation }(\mathrm{SD})\end{array}$ & $59.1 \pm 9.589$ & $52.2 \pm 4.1$ & $68.0 \pm 6.7$ & $<0.0001$ \\
\hline Depressive symptoms, mean \pm SD & $8.4 \pm 6.3$ & $7.8 \pm 6.2$ & $9.1 \pm 6.5$ & $<0.0001$ \\
\hline Depression, $n(\%)$ & $5270(36.6)$ & $3671(34.7)$ & $1599(41.8)$ & $<0.0001$ \\
\hline \multicolumn{5}{|l|}{ Gender, $n(\%)$} \\
\hline Male & $6932(48.2)$ & $4982(47.2)$ & $1950(50.9)$ & \multirow[t]{2}{*}{$<0.0001$} \\
\hline Female & $7460(51.8)$ & $5584(52.9)$ & $1876(49.1)$ & \\
\hline \multicolumn{5}{|l|}{ Residence, $n(\%)$} \\
\hline Rural & $6635(75.3)$ & $4683(75.3)$ & $1952(75.4)$ & \multirow[t]{2}{*}{0.9064} \\
\hline Urban & $2175(24.7)$ & $1538(24.7)$ & $637(24.6)$ & \\
\hline \multicolumn{5}{|l|}{ Education, $n(\%)$} \\
\hline Illiterate & $3781(26.7)$ & $2235(21.6)$ & $1546(40.9)$ & \multirow[t]{4}{*}{$<0.0001$} \\
\hline Elementary school & $5686(40.2)$ & $4125(39.8)$ & $1561(41.3)$ & \\
\hline Middle school & $3030(21.4)$ & $2630(25.4)$ & $400(10.6)$ & \\
\hline High school or above & $1644(11.6)$ & $1375(13.3)$ & $269(7.1)$ & \\
\hline \multicolumn{5}{|l|}{ Marital status, $n(\%)$} \\
\hline Married & $12677(88.1)$ & $9833(93.1)$ & $2844(74.3)$ & \multirow[t]{4}{*}{$<0.0001$} \\
\hline Divorced & $129(0.9)$ & $110(1.0)$ & $19(0.5)$ & \\
\hline Widowed & $1466(10.2)$ & $533(5.0)$ & $933(24.4)$ & \\
\hline Never married & $120(0.8)$ & $90(0.9)$ & $30(0.8)$ & \\
\hline \multicolumn{5}{|l|}{ Drinking status, $n(\%)$} \\
\hline None & $9668(67.2)$ & $6924(65.5)$ & $2744(71.7)$ & \multirow[t]{3}{*}{$<0.0001$} \\
\hline$<1 /$ month & $1107(7.7)$ & $873(8.3)$ & $234(6.1)$ & \\
\hline$\geq 1 /$ month & $3617(25.1)$ & $2769(26.2)$ & $848(22.2)$ & \\
\hline Abdominal obesity, $n(\%)$ & $6141(42.7)$ & $4603(43.6)$ & $1538(40.2)$ & 0.0003 \\
\hline \multicolumn{5}{|l|}{ Smoking status, $n(\%)$} \\
\hline Current smokers & $8673(60.3)$ & $6486(61.4)$ & $2187(57.2)$ & \multirow[t]{3}{*}{$<0.0001$} \\
\hline Never smokers & $4434(30.8)$ & $3297(31.2)$ & $1137(29.7)$ & \\
\hline Former smokers & $1282(8.9)$ & $781(7.4)$ & $501(13.1)$ & \\
\hline \multicolumn{5}{|l|}{ Sleep duration (h), $n(\%)$} \\
\hline$<6$ & $4260(29.6)$ & $2856(27.1)$ & $1404(36.7)$ & \multirow[t]{3}{*}{$<0.0001$} \\
\hline $6-9$ & $9541(66.3)$ & $7308(69.2)$ & $2233(58.4)$ & \\
\hline$>9$ & $591(4.1)$ & $402(3.8)$ & $189(4.9)$ & \\
\hline Mobility difficulty, $n(\%)$ & $9434(65.6)$ & $5024(55.1)$ & $4410(83.7)$ & $<0.001$ \\
\hline ADL difficulty, $n(\%)$ & $3732(38.4)$ & $2213(33.9)$ & $1519(47.8)$ & $<0.0001$ \\
\hline \multicolumn{5}{|l|}{ Health status, $n(\%)$} \\
\hline Poor & $490(3.4)$ & $309(2.9)$ & $181(4.73)$ & \multirow[t]{3}{*}{$<0.0001$} \\
\hline Good & $10005(69.5)$ & $7204(68.2)$ & $2801(73.21)$ & \\
\hline Excellent & $3897(27.1)$ & $3053(28.9)$ & $844(22.06)$ & \\
\hline Chronic pain, $n(\%)$ & $4574(31.8)$ & $3301(31.2)$ & $1273(33.28)$ & 0.0205 \\
\hline Life satisfaction, $n(\%)$ & & & & \\
\hline Perfect & $2880(22.2)$ & $2014(20.8)$ & $866(26.3)$ & $<0.0001$ \\
\hline Good & $8095(62.3)$ & $6100(62.9)$ & $1995(60.6)$ & \\
\hline Poor & $2010(15.5)$ & $1578(16.3)$ & $432(13.1)$ & \\
\hline Daily activities, $n(\%)$ & & & & \\
\hline Vigorous & $109(2.0)$ & $94(2.3)$ & $15(1.1)$ & $<0.0001$ \\
\hline Moderate & $427(7.8)$ & $349(8.5)$ & $78(5.7)$ & \\
\hline Walking & $4923(90.2)$ & $3650(89.2)$ & $1273(93.2)$ & \\
\hline Multimorbidity & $6222(43.2)$ & $2879(35.6)$ & $3343(52.9)$ & $<0.0001$ \\
\hline Number of chronic conditions & & & & \\
\hline 0 & $3831(26.6)$ & $3186(30.2)$ & $645(16.9)$ & $<0.0001$ \\
\hline 1 & $4339(30.2)$ & $3279(31.1)$ & $1060(27.7)$ & \\
\hline 2 & $3124(21.7)$ & $2156(20.1)$ & $968(25.3)$ & \\
\hline 3 & $1617(11.2)$ & $1052(9.9)$ & $565(14.8)$ & \\
\hline$\geq 4$ & $1481(10.3)$ & $893(8.5)$ & $588(15.4)$ & \\
\hline
\end{tabular}

The total amount of moderate to vigorous physical activity over the last week was calculated and those scoring $<150$ min were considered to have low physical activity; Data are unweighted $n$ and weighted proportion or mean (standard deviation: SD); Data are weighted column \% unless otherwise stated; The differences in sample characteristics between age groups were tested by Chi-squared tests. 
Table 2 The prevalence of chronic conditions, multimorbidiy, and number of chronic conditions among the analytical sample

\begin{tabular}{|c|c|c|c|c|c|c|c|}
\hline \multirow{2}{*}{ Chronic disease } & \multirow{2}{*}{ Total } & \multicolumn{3}{|c|}{ Age (years) } & \multicolumn{3}{|c|}{ Gender } \\
\hline & & $45-64$ & $\geq 65$ & $P$-value & Male & Female & $P$-value \\
\hline Hypertension, $n(\%)$ & $3690(49.06)$ & $2269(41.59)$ & $1421(68.78)$ & $<0.0001$ & $1737(47.64)$ & $1953(50.40)$ & 0.0168 \\
\hline Diabetes, $n(\%)$ & $1081(22.01)$ & $742(18.89)$ & $339(34.45)$ & $<0.0001$ & $460(19.42)$ & $621(24.42)$ & $<0.0001$ \\
\hline Dyslipidemia, $n(\%)$ & $1334(25.83)$ & $958(23.12)$ & $376(36.83)$ & $<0.0001$ & $615(24.37)$ & $719(27.22)$ & 0.0190 \\
\hline Cancer, $n(\%)$ & $138(3.48)$ & $98(2.98)$ & $40(5.84)$ & 0.0002 & $47(2.40)$ & $91(4.52)$ & 0.0003 \\
\hline Chronic lung disease, $n(\%)$ & $1471(27.74)$ & $887(21.78)$ & $584(47.52)$ & $<0.0001$ & $832(30.35)$ & $639(24.95)$ & $<0.0001$ \\
\hline Liver disease, $n(\%)$ & 575 & 435 & 140 & $<0.0$ & $307(13.85)$ & 12.24) & 0.1113 \\
\hline Heart fa & $1754(31.41)$ & $1115(25.92)$ & $639(49.77)$ & $<0.0001$ & $685(26.41)$ & $1069(35.74)$ & $<0.0001$ \\
\hline Stroke, $n(\%)$ & $299(7.24)$ & $167(4.98)$ & $132(16.99)$ & $<0.0001$ & $150(7.29)$ & 149 & 0.9107 \\
\hline kidney disease & $912(19.23)$ & $673(17.44)$ & $239(27.04)$ & $<0.0001$ & $491(20.46)$ & $421(17.97)$ & 0.0296 \\
\hline Digestive disease, $n(\%)$ & $3223(45.69)$ & $2421(43.18)$ & $802(55.43)$ & $<0.0001$ & $1412(42.52)$ & $1811(48.51)$ & $<0.0001$ \\
\hline Arthritis or rheumatism, $n(\%)$ & $4799(55.61)$ & $3418(51.76)$ & $1381(68.16)$ & $<0.0001$ & $2009(51.28)$ & $2790(59.21)$ & $<0.0001$ \\
\hline Asthma, $n(\%)$ & $501(11.57)$ & $274(7.92)$ & $227(26.03)$ & $<0.0001$ & $291(13.23)$ & $210(9.85)$ & 0.0005 \\
\hline Multimorbidity, $n(\%)$ & $6222(43.23)$ & $4101(38.81)$ & $2121(55.44)$ & $<0.0001$ & $2864(41.32)$ & $3358(45.01)$ & $<0.001$ \\
\hline
\end{tabular}

Moreover, the result of stratification presented that the prevalence of the assessed twelve chronic diseases among the elderly was much higher than the middle aged ones. Especially the prevalence of diabetes, chronic lung disease, heart failure, and cancer among the elderly was almost two times that of the middle aged ones, while the prevalence of stroke and asthma was more than three times than the middle aged people. As for the gender stratification, we can see that the male had higher prevalence of chronic lung disease, kidney disease, and asthma, while the female had higher prevalence of hypertension, diabetes, dyslipidemia, cancer, heart failure, digestive disease, and arthritis. Since all the chronic diseases, excepting for hypertension and diabetes, were based on self-reported, the reporting bias which could arouse bias estimation of the true prevalence could not be neglected.

Table 3 Cross-sectional associations between chronic diseases and number of chronic diseases with depressive symptoms (outcome) estimated by logistic regression

\begin{tabular}{|c|c|c|c|c|c|c|}
\hline \multirow{2}{*}{ Chronic disease } & \multicolumn{2}{|c|}{ Model 1} & \multicolumn{2}{|c|}{ Model 2} & \multicolumn{2}{|c|}{ Model 3} \\
\hline & OR $(95 \% \mathrm{CI})$ & $P$-value & OR $(95 \% \mathrm{CI})$ & $P$-value & OR $(95 \% \mathrm{CI})$ & $P$-value \\
\hline Hypertension & $2.34(2.06,2.65)$ & $<0.001$ & $2.15(1.83,2.53)$ & 0.001 & $1.22(0.81,1.85)$ & 0.348 \\
\hline Diabetes & $2.56(2.14,3.06)$ & $<0.001$ & $2.60(2.04,3.31)$ & $<0.001$ & $2.13(1.29,3.51)$ & 0.003 \\
\hline Dyslipidemia & $2.17(1.83,2.57)$ & $<0.001$ & $2.59(2.11,3.19)$ & $<0.001$ & $1.42(0.83,2.43)$ & 0.203 \\
\hline Cancer & $3.25(2.25,4.70)$ & $<0.001$ & $2.58(1.56,4.26)$ & 0.002 & $2.52(0.80,7.93)$ & 0.111 \\
\hline Chronic lung disease & $3.37(2.88,3.94)$ & $<0.001$ & $3.23(2.58,4.05)$ & $<0.001$ & $1.66(1.08,2.55)$ & 0.020 \\
\hline Liver disease & $3.01(2.43,3.75)$ & $<0.001$ & $3.33(2.57,4.30)$ & $<0.001$ & $1.67(0.96,2.89)$ & 0.067 \\
\hline Heart failure & $3.59(3.16,4.08)$ & $<0.001$ & $3.64(3.01,4.41)$ & $<0.001$ & $2.51(1.54,4.11)$ & $<0.001$ \\
\hline Stroke & $4.19(3.22,5.46)$ & $<0.001$ & $3.74(2.43,5.76)$ & $<0.001$ & $1.94(0.79,4.78)$ & 0.145 \\
\hline Kidney disease & $3.50(2.90,4.22)$ & $<0.001$ & $3.89(3.11,4.86)$ & $<0.001$ & $1.52(0.92,2.51)$ & 0.103 \\
\hline Stomach or other digestive disease & $3.25(2.90,3.64)$ & $<0.001$ & $3.07(2.63,3.59)$ & $<0.001$ & $1.02(0.68,1.53)$ & 0.927 \\
\hline Arthritis or rheumatism & $3.25(2.92,3.62)$ & $<0.001$ & $2.82(2.46,3.24)$ & $<0.001$ & $1.29(0.91,1.82)$ & 0.152 \\
\hline Asthma & $4.41(3.54,5.49)$ & $<0.001$ & $4.73(3.44,6.50)$ & $<0.001$ & $2.87(1.68,4.92)$ & $<0.0001$ \\
\hline \multicolumn{7}{|l|}{ Number of disease } \\
\hline 1 & $1.43(1.29,1.59)$ & $<0.001$ & $1.24(1.07,1.44)$ & $<0.001$ & $0.74(0.53,1.07)$ & 0.107 \\
\hline 2 & $2.45(2.17,2.77)$ & $<0.001$ & $2.10(1.80,2.45)$ & $<0.001$ & $1.32(0.91,1.93)$ & 0.147 \\
\hline 3 & $3.51(3.01,4.09)$ & $<0.001$ & $3.37(2.78,4.10)$ & $<0.001$ & $1.88(1.18,2.99)$ & 0.007 \\
\hline$\geq 4$ & $4.99(4.23,5.89)$ & $<0.001$ & $5.21(4.00,6.79)$ & $<0.001$ & $2.04(1.24,3.35)$ & 0.005 \\
\hline
\end{tabular}

Model 1: the raw analysis without adjusting for any covariates; Model 2: adjusting for age cognition, gender, marital status, education, residence; Model 3: adjusting for age, gender, marital status, education, residence, smoking status, drinking, BMI status, central obesity, daily activities, sleep duration, self-reported health, self-reported life satisfaction, ADL disability and chronic body pain

The results of the multivariable logistic regression analysis assessing the cross-sectional association between chronic diseases and depression are shown in table 3. In the overall sample, all 12 specific chronic diseases, and multimorbidity, were significantly associated with depression in the raw model. However, after adjusting for some covariates including functional health symptoms, only diabetes, chronic lung disease, heart failure and asthma were associated with depression (model 3). In terms of the number of chronic diseases, compared with participants without any chronic diseases, the association between depression and chronic diseases exhibited a linear trend with increasing OR, ranging from $\mathrm{OR}=1.432(95 \% \mathrm{CI}$ : $1.286,1.594)$ for participants with only one chronic disease to OR $=4.990(95 \%$ CI: 4.229, 5.889) for those with more than three chronic diseases in model 1 . The same trend was observed in model 2 and model 3, indicating that participants with more chronic diseases had a higher risk of depression. 
Regarding the longitudinal association, 9104 participants completed the wave II and wave III survey and the measurement of depression. In this sample, $49.40 \%$ of participants were male, and $21.56 \%$ were aged $\geq 65$ years. It should be noted that there were 5863 participants with CES-D-10 scores $<10$ at baseline, and $18.01 \%$ of them had incident depression (CES-D-10 $\geq 10$ ) at the 2013 survey and $13.10 \%$ had incident depression (CES-D-10 $\geq 10$ ) at the 2015 survey. The results from the raw model revealed that all 12 estimated chronic diseases were associated with depression. However, after adjusting for covariates, only diabetes, chronic lung disease, heart failure, stroke, kidney disease, arthritis or rheumatism, and asthma at baseline were found to be significant risk factors for the incidence of depression, with asthma having the highest OR $(2.446 ; 95 \%$ CI: $1.625,3.683)$ (model 3). In addition, multimorbidity with more than three chronic diseases also increased the risk of depression $(\mathrm{OR}=1.858 ; 95 \% \mathrm{CI}: 1.394,2.477)$. The details of these results are shown in table 4 .

\subsection{Mediation Analysis}

The indirect effect between chronic diseases and incident depression was significant in all analyses. Regarding specific chronic diseases, mobility difficulties explained more than $30 \%$ of the association for all chronic diseases, with particularly high mediated percentages observed for stroke $(51.56 \%)$ and cancer (51.06\%). ADL mediated $19.15 \%$ (hypertension) to $34.6 \%$ (stroke) of the association between chronic diseases and depression. Chronic pain was another major mediator of the association between depression and all chronic diseases, and explained more than 30\% of the association for all chronic diseases, ranging from $31.91 \%$ (diabetes) to $53.35 \%$ (cancer). Sleep problems did not explain the association of depression with hypertension, diabetes, dyslipidemia, and cancer. For other conditions, sleep problems explained from $10.15 \%$ (stroke) to $14.89 \%$ (chronic lung disease) of the association. However, cognitive problems were not found to be an influential factor in the association of depression with chronic diseases or multimorbidity in this study. Regarding multimorbidity, the results revealed that ADL, mobility difficulties, sleep and chronic pain mediated $19.61 \%, 31.68 \%, 12.33 \%$ and $34.57 \%$ of the association, respectively. The detailed mediation analysis is shown in table 5.

\section{DISCUSSION}

The current findings demonstrated a close relationship between chronic disease/multimorbidity and depression, indicating that people with chronic diseases are at a higher risk of being depressed or suffering from depressive symptoms. In patients with diabetes, stroke, or arthritis, chronic disease had a particularly strong influence on the incidence of depression. Moreover, participants with a greater number of chronic diseases had a higher risk of being depressed, and the risk was proportional to the number of chronic diseases. These findings highlight the importance of paying more attention to the impact of chronic diseases on patients' mental health during the diagnosis and treatment process. In addition, the correlation analysis revealed that all of the chronic diseases assessed in this study were associated with depressive symptoms, independent of other covariates. The mediation analyses for the whole sample revealed

Table 4 Longitudinal associations of chronic diseases, and multimorbidity with depression (defined as CES-D $\geq 10$ ) estimated by GEE model

\begin{tabular}{|c|c|c|c|c|c|c|}
\hline \multirow{2}{*}{ Chronic disease } & \multicolumn{2}{|c|}{ Model 1} & \multicolumn{2}{|c|}{ Model 2} & \multicolumn{2}{|c|}{ Model 3} \\
\hline & OR $(95 \% \mathrm{CI})$ & $P$-value & OR $(95 \% \mathrm{CI})$ & $P$-value & OR $(95 \% \mathrm{CI})$ & $P$-value \\
\hline Hypertension & $1.57(1.44,1.75)$ & $<0.001$ & $1.46(1.28,1.66)$ & $<0.001$ & $1.17(0.93,1.46)$ & 0.186 \\
\hline Diabetes & $1.87(1.63,2.13)$ & $<0.001$ & $1.86(1.56,2.22)$ & $<0.001$ & $1.43(1.05,1.95)$ & 0.024 \\
\hline Dyslipidemia & $1.63(1.44,1.85)$ & $<0.001$ & $1.81(1.55,2.12)$ & $<0.001$ & $1.27(0.96,1.68)$ & 0.101 \\
\hline Chronic lung disease & $2.75(2.45,3.08)$ & $<0.001$ & $2.75(2.38,3.19)$ & $<0.001$ & $1.54(1.20,1.99)$ & 0.001 \\
\hline Liver disease & $2.26(1.91,2.68)$ & $<0.001$ & $2.53(2.05,3.12)$ & $<0.001$ & $1.15(0.80,1.66)$ & 0.446 \\
\hline Heart failure & $2.52(2.25,2.83)$ & $<0.001$ & $2.46(2.12,2.86)$ & $<0.001$ & $1.62(1.26,2.09)$ & $<0.001$ \\
\hline Stroke & $2.68(2.07,3.47)$ & $<0.001$ & $2.83(1.99,4.02)$ & $<0.001$ & $1.83(1.06,3.16)$ & 0.031 \\
\hline Kidney disease & $2.83(2.47,3.26)$ & $<0.001$ & $3.14(2.63,3.74)$ & $<0.001$ & $1.35(1.02,1.81)$ & 0.044 \\
\hline Digestive disease & $2.50(2.28,2.74)$ & $<0.001$ & $2.37(2.12,2.66)$ & $<0.001$ & $1.12(0.91,1.38)$ & 0.279 \\
\hline Arthritis or rheumatism & $2.56(2.36,2.78)$ & $<0.001$ & $2.32(2.08,2.58)$ & $<0.001$ & $1.30(1.08,1.56)$ & 0.006 \\
\hline Asthma & $3.45(2.83,4.23)$ & $<0.001$ & $3.57(2.77,4.60)$ & $<0.001$ & $2.45(1.63,3.68)$ & $<0.001$ \\
\hline \multicolumn{7}{|l|}{ Number of disease } \\
\hline 1 & $1.43(1.31,1.57)$ & $<0.001$ & $1.31(1.17,1.47)$ & $<0.001$ & $0.96(0.79,1.16)$ & 0.678 \\
\hline 2 & $1.95(1.78,2.15)$ & $<0.001$ & $1.81(1.60,2.05)$ & $<0.001$ & $1.22(0.99,1.50)$ & 0.056 \\
\hline 3 & $2.50(2.21,2.82)$ & $<0.001$ & $2.36(2.02,2.75)$ & $<0.001$ & $1.23(0.95,1.58)$ & 0.113 \\
\hline$\geq 4$ & $3.58(3.12,4.12)$ & $<0.001$ & $3.75(3.13,4.49)$ & $<0.001$ & $1.86(1.39,2.48)$ & $<0.001$ \\
\hline
\end{tabular}

Model 0: the raw analysis without adjusting for any covariates; Model 1: adjusting for age cognition, gender, martial status, education, residence; Model 3: adjusting for age, gender, martial status, education, residence, smoking status, drinking, BMI status, central obesity, daily activities, sleep duration, self-reported health, self-reported life satisfaction, ADL disability and chronic body pain 
Table 5 ADL, mobility, chronic pain and sleep as mediators in the association between chronic diseases (multimorbidity) and depression among adults aged $\geq 45$ years

\begin{tabular}{|c|c|c|c|c|c|c|c|c|}
\hline \multirow{2}{*}{ Mediator } & \multirow{2}{*}{ Exposure } & \multicolumn{2}{|c|}{ Total effect } & \multicolumn{2}{|c|}{ Direct effect } & \multicolumn{2}{|c|}{ Indirect effect } & \multirow{2}{*}{$\begin{array}{c}\% \\
\text { Mediated }\end{array}$} \\
\hline & & $\beta(95 \% \mathrm{CI})$ & $P$-value & $\beta(95 \% \mathrm{CI})$ & $P$-value & $\beta(95 \% \mathrm{CI})$ & $P$-value & \\
\hline \multicolumn{9}{|l|}{ Mobility } \\
\hline & Hypertension & $1.84(1.58,2.15)$ & $<0.001$ & $1.45(1.24,1.69)$ & $<0.001$ & $1.27(1.12,1.44)$ & $<0.001$ & 39.23 \\
\hline & Diabetes & $2.60(2.10,3.22)$ & $<0.001$ & $1.69(1.36,2.11)$ & $<0.001$ & $1.53(1.30,1.81)$ & $<0.001$ & 44.81 \\
\hline & Dyslipidemia & $2.32(1.90,2.84)$ & $<0.001$ & $1.54(1.25,1.89)$ & $<0.001$ & $1.51(1.29,1.76)$ & $<0.001$ & 48.73 \\
\hline & Cancer & $2.73(1.67,4.48)$ & $<0.001$ & $1.64(0.99,2.70)$ & 0.054 & $1.67(1.37,2.04)$ & $<0.001$ & 51.06 \\
\hline & Chronic lung disease & $3.33(2.77,4.00)$ & $<0.001$ & $2.08(1.72,2.52)$ & $<0.001$ & $1.60(1.38,1.86)$ & $<0.001$ & 39.02 \\
\hline & Liver disease & $3.36(2.60,4.35)$ & $<0.001$ & $1.98(1.52,2.58)$ & $<0.001$ & $1.70(1.42,2.03)$ & $<0.001$ & 43.65 \\
\hline & Heart failure & $3.64(3.04,4.36)$ & $<0.001$ & $2.11(1.75,2.54)$ & $<0.001$ & $1.73(1.47,2.03)$ & $<0.001$ & 42.33 \\
\hline & Stroke & $4.35(3.03,6.25)$ & $<0.001$ & $2.04(1.40,2.97)$ & $<0.001$ & $2.13(1.72,2.65)$ & $<0.001$ & 51.56 \\
\hline & Kidney disease & $4.48(3.61,5.56)$ & $<0.001$ & $2.78(2.23,3.46)$ & $<0.001$ & $1.62(1.38,1.89)$ & $<0.001$ & 31.94 \\
\hline & Digestive disease & $3.15(2.73,3.64)$ & $<0.001$ & $2.06(1.78,2.39)$ & $<0.001$ & $1.53(1.31,1.78)$ & $<0.001$ & 37.00 \\
\hline & Arthritis & $3.04(2.66,3.47)$ & $<0.001$ & $2.07(1.81,2.37)$ & $<0.001$ & $1.47(1.30,1.66)$ & $<0.001$ & 34.62 \\
\hline & Asthma & $4.31(3.27,5.68)$ & $<0.001$ & $2.46(1.86,3.27)$ & $<0.001$ & $1.75(1.47,2.08)$ & $<0.001$ & 38.26 \\
\hline & Multimorbidity & $2.67(2.42,2.95)$ & $<0.001$ & $1.96(1.77,2.17)$ & $<0.001$ & $1.37(1.25,1.50)$ & $<0.001$ & 31.68 \\
\hline \multicolumn{9}{|c|}{ Chronic pain } \\
\hline & Hypertension & $1.80(1.54,2.10)$ & $<0.001$ & $1.43(1.23,1.67)$ & $<0.001$ & $1.26(1.12,1.41)$ & 0.018 & 38.80 \\
\hline & Diabetes & $2.48(2.01,3.07)$ & $<0.001$ & $1.86(1.50,2.30)$ & $<0.001$ & $1.34(1.17,1.52)$ & 0.001 & 31.91 \\
\hline & Dyslipidemia & $2.25(1.84,2.75)$ & $<0.001$ & $1.51(1.23,1.86)$ & $<0.001$ & $1.49(1.29,1.72)$ & $<0.001$ & 48.88 \\
\hline & Cancer & $2.62(1.60,4.28)$ & $<0.001$ & $1.57(0.95,2.58)$ & & $1.67(1.34,2$. & 0.012 & 53.35 \\
\hline & Chronic lung disease & $3.27(2.72,3.94)$ & $<0.001$ & $1.97(1.63,2.38)$ & $<0.001$ & $1.66(1.42,1.95)$ & 0.001 & 42.86 \\
\hline & Liver disease & $3.17(2.46,4.10)$ & $<0.001$ & $1.87(1.44,2.44)$ & $<0.001$ & $1.69(1.43,2.00)$ & $<0.001$ & 45.61 \\
\hline & Heart failure & $3.52(2.94,4.22)$ & $<0.001$ & $2.21(1.83,2.65)$ & $<0.001$ & $1.60(1.38,1.85)$ & $<0.001$ & 37.18 \\
\hline & Stroke & $4.02(2.83,5.73)$ & $<0.001$ & $2.44(1.71,3.50)$ & $<0.001$ & $1.65(1.38,1.97)$ & $<0.001$ & 35.83 \\
\hline & Kidney disease & $4.38(3.52,5.45)$ & $<0.001$ & $2.28(1.81,2.87)$ & $<0.001$ & $1.92(1.62,2.28)$ & $<0.001$ & 44.13 \\
\hline & Digestive disease & $3.02(2.61,3.48)$ & $<0.001$ & $1.84(1.58,2.14)$ & $<0.001$ & $1.64(1.43,1.87)$ & 0.001 & 44.77 \\
\hline & Arthritis & $2.99(2.62,3.41)$ & $<0.001$ & $1.89(1.64,2.17)$ & $<0.001$ & $1.58(1.41,1.78)$ & $<0.001$ & 42.01 \\
\hline & Asthma & $4.13(3.13,5.45)$ & $<0.001$ & $2.43(1.83,3.22)$ & $<0.001$ & $1.70(1.44,2.02)$ & $<0.001$ & 37.49 \\
\hline & Multimorbidity & $2.77(2.51,3.06)$ & $<0.001$ & $1.95(1.76,2.16)$ & $<0.001$ & $1.42(1.30,1.55)$ & 0.026 & 34.57 \\
\hline \multicolumn{9}{|l|}{$\mathrm{ADL}$} \\
\hline & Hypertension & $1.81(1.56,2.1)$ & $<0.001$ & $1.62(1.39,1.88)$ & $<0.001$ & $1.12(1.03,1.21)$ & 0.006 & 19.15 \\
\hline & Diabetes & $2.50(2.02,3.08)$ & $<0.001$ & $2.05(1.66,2.54)$ & $<0.001$ & $1.21(1.09,1.36)$ & 0.001 & 21.27 \\
\hline & Dyslipidemia & $2.27(1.87,2.77)$ & $<0.001$ & $1.79(1.46,2.18)$ & $<0.001$ & $1.27(1.14,1.42)$ & $<0.001$ & 29.32 \\
\hline & Cancer & $2.64(1.63,4.27)$ & $<0.001$ & $2.02(1.25,3.28)$ & 0.004 & $1.30(1.10,1.54)$ & 0.002 & 27.34 \\
\hline & Chronic lung disease & $3.23(2.70,3.87)$ & $<0.001$ & $2.54(2.12,3.05)$ & $<0.001$ & $1.27(1.14,1.42)$ & 0.001 & 20.46 \\
\hline & Liver disease & $3.18(2.47,4.10)$ & $<0.001$ & $2.27(1.75,2.94)$ & $<0.001$ & $1.40(1.22,1.61)$ & $<0.001$ & 29.25 \\
\hline & Heart failure & $3.49(2.92,4.16)$ & $<0.001$ & $2.65(2.21,3.16)$ & $<0.001$ & $1.32(1.18,1.47)$ & $<0.001$ & 22.14 \\
\hline & Stroke & $4.00(2.82,5.69)$ & $<0.001$ & $2.48(1.73,3.55)$ & $<0.001$ & $1.62(1.37,1.91)$ & $<0.001$ & 34.60 \\
\hline & Kidney disease & $4.32(3.50,5.35)$ & $<0.001$ & $3.18(2.57,3.95)$ & $<0.001$ & $1.36(1.20,1.54)$ & $<0.001$ & 20.90 \\
\hline & Digestive disease & $3.01(2.61,3.46)$ & $<0.001$ & $2.37(2.06,2.73)$ & $<0.001$ & $1.27(1.15,1.40)$ & 0.001 & 21.63 \\
\hline & Arthritis & $2.96(2.60,3.37)$ & $<0.001$ & $2.37(2.07,2.70)$ & $<0.001$ & $1.25(1.15,1.36)$ & $<0.001$ & 20.59 \\
\hline & Asthma & $4.11(3.13,5.4)$ & $<0.001$ & $3.04(2.31,4.00)$ & $<0.001$ & $1.35(1.18,1.55)$ & $<0.001$ & 21.35 \\
\hline & Multimorbidity & $2.72(2.47,3.00)$ & $<0.001$ & $2.23(2.02,2.46)$ & $<0.001$ & $1.22(1.14,1.29)$ & 0.026 & 19.61 \\
\hline \multicolumn{9}{|l|}{ Sleep } \\
\hline & Hypertension & $1.83(1.57,2.12)$ & $<0.001$ & $1.69(1.46,1.97)$ & $<0.001$ & $1.08(0.98,1.18)$ & 0.112 & NA \\
\hline & Diabetes & $2.50(2.03,3.07)$ & $<0.001$ & $2.34(1.90,2.88)$ & $<0.001$ & $1.07(0.97,1.17)$ & 0.173 & NA \\
\hline & Dyslipidemia & $2.29(1.88,2.78)$ & $<0.001$ & $2.14(1.76,2.60)$ & $<0.001$ & $1.07(0.97,1.18)$ & 0.186 & NA \\
\hline & Cancer & $2.50(1.54,4.04)$ & $<0.001$ & $2.24(1.39,3.62)$ & 0.001 & $1.11(0.98,1.27)$ & 0.111 & NA \\
\hline & Chronic lung disease & $3.23(2.7,3.87)$ & $<0.001$ & $2.72(2.27,3.25)$ & $<0.001$ & $1.19(1.07,1.32)$ & 0.001 & 14.89 \\
\hline & Liver disease & $3.19(2.49,4.09)$ & $<0.001$ & $2.74(2.14,3.52)$ & $<0.001$ & $1.16(1.04,1.30)$ & 0.007 & 13.09 \\
\hline & Heart failure & $3.52(2.95,4.19)$ & $<0.001$ & $3.03(2.55,3.62)$ & $<0.001$ & $1.16(1.04,1.29)$ & 0.006 & 11.71 \\
\hline & Stroke & $3.95(2.79,5.57)$ & $<0.001$ & $3.43(2.43,4.84)$ & $<0.001$ & $1.15(1.02,1.29)$ & 0.019 & 10.15 \\
\hline & Kidney disease & $4.38(3.53,5.42)$ & $<0.001$ & $3.62(2.92,4.47)$ & $<0.001$ & $1.21(1.07,1.38)$ & 0.003 & 12.94 \\
\hline & Digestive disease & $3.02(2.62,3.47)$ & $<0.001$ & $2.57(2.24,2.96)$ & $<0.001$ & $1.17(1.06,1.29)$ & 0.001 & 14.42 \\
\hline & Arthritis & $3.02(2.65,3.45)$ & $<0.001$ & $2.58(0.70,9.54)$ & $<0.001$ & $1.17(1.07,1.28)$ & 0.001 & 14.20 \\
\hline & Asthma & $4.20(3.20,5.52)$ & $<0.001$ & $3.62(2.76,4.75)$ & $<0.001$ & $1.16(1.03,1.31)$ & 0.015 & 10.30 \\
\hline & Multimorbidity & $2.62(2.38,2.89)$ & $<0.001$ & $2.33(2.11,2.57)$ & $<0.001$ & $1.13(1.05,1.20)$ & 0.001 & 12.33 \\
\hline
\end{tabular}


that mobility difficulties, chronic pain, limited ADL and sleep problems were important factors for most of the chronic diseases studied, and the mediation proportion ranged from approximately $30 \%$ to $60 \%$. Sleep and limited ADL also mediated a relatively large proportion (approximately $15 \%$ to $30 \%$ ) of the relationship between depression and chronic diseases. The identification of mediators offers potential targets for future public health interventions. For example, participants with arthritis were more likely to be depressed and this significant association was largely mediated by chronic pain $(42.01 \%)$, followed by mobility difficulties (34.62\%), limited ADL (20.59\%) and sleep problems $(14.20 \%)$, suggesting that more attention should be paid to the control of patients' pain during the arthritis diagnosis process.

The prevalence rates of both depression and chronic disease are increasing. As reported in the present study, the prevalence of chronic disease was high among middle-aged and elderly Chinese individuals, and the prevalence of arthritis and rheumatism had the highest prevalence, at $55.61 \%$. Importantly, arthritis had a much higher prevalence rate of $68.16 \%$ among people aged $\geq 65$, indicating that almost two thirds of elderly individuals suffered from severe arthritis. Furthermore, arthritis was associated with pain, which could also cause mobility difficulties and ADL limitations, as well as sleep problems ${ }^{[37]}$. Research interest in the relationship between chronic diseases and depression has been increasing. Ni et al reported that having a chronic disease was a significant explanatory factor for an increased likelihood of depression ${ }^{[38]}$. Increased prevalence of depression has also been reported in patients with cardiovascular disease ${ }^{[39,40]}$, hypertension ${ }^{[41]}$, diabetes ${ }^{[42,}{ }^{43]}, \operatorname{arthritis}^{[44-46]}$, and multimorbidity ${ }^{[47,48]}$. In addition to the high prevalence of specific chronic diseases, multimorbidity is an even more serious issue among Chinese middleaged and elderly individuals. In addition to the high prevalence of multimorbidity $(43.23 \%$ in the combined middle-aged and elderly sample, and $55.44 \%$ among those aged $\geq 65$ ), we also demonstrated a relationship between multimorbidity and depression, indicating that people with multimorbidity had a higher risk of depressive disorder than those without multimorbidity, and faced 2.25 times the risk of depression compared with those with no chronic disease. Multimorbidity has been reported to increase patients' symptom burden, leading to disability and decreased quality of life ${ }^{[49]}$. Multimorbidity could also increase the discomfort associated with chronic pain and exert negative effects on health-related beliefs, and financial burden of treatment for patients with multimorbidity could also increase negative feelings, thus increasing the likelihood of depressive symptoms.

Previous studies have used various approaches to address the relationships between depression and chronic diseases, including Becks Developmental Model of Depression ${ }^{[50]}$, which indicates that depressive symptoms are negative interpretations of an individual's experience, which can result from chronic diseases or multimorbidity. In addition, the Activity Restriction Model of Depressed Affect ${ }^{[51]}$ indicates that depressive symptoms are due to the psychological impacts of having to give up valued activities in response to chronic illness. The Psychological and Biological Pathways Model ${ }^{[52]}$ proposes that having a chronic disease can result in a decreased ability to implement strategies that help maintain control of important aspects of patients' lives, and that this, in conjunction with neurochemical and neuroanatomical changes associated with illness, may result in depressive symptoms.

Psychological or biological mechanisms might provide an explanation of the structural and neurochemical changes of the brain that lead to depression, but interventions in daily practice may not be effective. To inform improved management of depression through daily interventions among patients with chronic diseases or multimorbidity was more meaningful and had practical effect. Through the mediation analysis, it is revealed that chronic pain, mobility difficulty, limited ADL, and poor sleep mediated the relationship between chronic diseases and depressive symptoms in the middle-aged and elderly individuals, indicating that those mediators play an explanatory role in addition to the unpredictable course of chronic illnesses. Furthermore, mobility difficulties and pain exerted stronger mediating effects on the incidence of depression, particularly among cancer patients $(51.06 \%$ and $53.35 \%$ mediated, respectively). Limited ADL and mobility difficulties exerted the strongest mediating effects in the incidence of depression among participants suffering from stroke (34.60\% and $51.56 \%$ mediated, respectively). The mediating effect of poor sleep was weaker than that of the other three indicators. However, the mediating effects of poor sleep should not be neglected, particularly in patents with digestive disease or chronic lung disease.

Chronic pain, mobility difficulty, limited ADL, and poor sleep are common functional symptoms in patients with chronic diseases, particularly in those with multimorbidity. Chronic pain can be caused by underlying systemic disease, and is commonly involved in cancer, arthritis, chronic lung disease, kidney disease, digestive disease, and liver disease ${ }^{[36]}$. Daily feelings of chronic pain could seriously affect physical and mental health of people and reduce their quality of life ${ }^{[53]}$, and thus lead to or impose high burden of depression. As reported by Gerrits et al, the prevalence of chronic pain in patients who were under treatment for depression was about $51.8 \%$ to $59.1 \%{ }^{[54]}$. 
Mobility difficulty and limited ADL can also occur in certain chronic diseases, and can lead to depression and severely impact daily lives or personal emotions, providing an explanatory role for the pathways of chronic diseases to depression. Sleeping problem was another daily unhappy feeling and could play certain roles in the pathway to depression development. Most chronic diseases could lead to sleeping problems through somatic discomfort or biologic mechanisms. Poor sleep was associated with depression, and vice versa. The mutual relationship between poor sleep, chronic diseases, as well as depression was a loop, and will be influenced by each other. Multidisciplinary research is increasingly popular in various research fields, and important aspects of the management of chronic diseases and depression can be considered using a multidisciplinary approach to simultaneously focus on both physical symptoms and physical health outcomes. As the most populous country in the world, the challenges of population aging in China are serious and urgent. Thus, health-related interventions regarding effective and sustainable primary and secondary interventions warrant more research attention. Awareness of public health and the importance of effective interventions for depression by improving daily activities in patients with chronic diseases, particularly those with multimorbidity, should be addressed and increased.

This study involved several limitations that should be considered when interpreting the current findings. First, although the CHARLS has a longitudinal design, we failed to obtain information about incident illness, and were consequently unable to investigate the relationship between incident chronic illness and depression, and vice versa. However, we obtained CES-D-10 results at three surveys, and were thus able to assess newly depressed participants and evaluate the longitudinal association between the prevalence of chronic illness and the incidence of depression, confirming a causal effect between chronic illness and depression. Second, considering the long period of the follow-up interval, in which many health conditions could have emerged or changed, the longitudinal assessment may have been biased. However, the diagnosed chronic illnesses, as well as the covariates assessed in our research, have a long duration, supporting the reliability of our longitudinal analyses. Third, depression involves negative emotional experience, and may negatively influence a person's impression of their own health, resulting in depressed individuals being more likely to make health-related complaints such as poor sleep, chronic pain, and more severe mobility difficulties or limited ADL, potentially causing overestimation of the strength of the associations between chronic diseases and depression ${ }^{[55]}$. However, we examined a relatively large sample in our initial attempt to estimate the relationship between chronic disease and depression among middle-aged and elderly Chinese individuals, and explored the mediating effect of four physical symptoms related to mobility, pain, limited ADL, and sleep. Although some pathways relating to depression are well established, most previous studies have focused on a small number of chronic diseases, and have not conducted comparisons to identify common features. Therefore, the comprehensive results in the current study could be helpful for elucidating different impacts of various chronic diseases in the course of depression, providing useful information for informing effective interventions and improving daily living quality in patients with chronic conditions.

To sum up, the present findings revealed that individuals with chronic diseases or multimorbidity are significantly more likely to be depressed than healthy individuals, and certain symptoms may mediate the association between chronic disease and depression. Research attention and chronic disease management should be focused on the clinical management of diabetes, chronic lung disease, heart failure, asthma, and multimorbidity. Research on effective interventions focused on improving functional symptoms involving mobility difficulties and limited ADL may be useful for ameliorating associated depression among individuals with chronic diseases, and should be a priority for funding bodies.

\section{Open Access}

This article is licensed under a Creative Commons Attribution 4.0 International License https://creativecommons.org/licenses/by/4.0/), which permits use, sharing, adaptation, distribution and reproduction in any medium or format, as long as you give appropriate credit to the original author(s) and the source, provide a link to the Creative Commons licence, and indicate if changes were made. The images or other third party material in this article are included in the article's Creative Commons licence, unless indicated otherwise in a credit line to the material. If material is not included in the article's Creative Commons licence and your intended use is not permitted by statutory regulation or exceeds the permitted use, you will need to obtain permission directly from the copyright holder. To view a copy of this licence, visit http://creativecommons.org/licenses/by/4.0/.

\section{Acknowledgments}

We thank Benjamin Knight, MSc., from Liwen Bianji, Edanz Editing China (www.liwenbianji.cn/ac), for editing the English text of a draft of this manuscript.

\section{Conflict of Interest Statement}

The authors have declared no conflicts of interest for this article.

\section{REFERENCES}

1 Zeng Y. Towards Deeper Research and Better Policy 
for Healthy Aging --Using the Unique Data of Chinese Longitudinal Healthy Longevity Survey. China Economic J, 2012,5(2-3):131-149

2 Fang EF, Scheibye-Knudsen M, Jahn HJ, et al. A research agenda for aging in China in the 21 st century. Age Res Rev, 2015,24(Pt B):197-205

3 Yang G, Wang Y, Zeng Y, et al. Rapid health transition in China, 1990-2010: findings from the Global Burden of Disease Study 2010. Lancet, 2013,381(9882):19872015

4 Yu J, Li J, Cuijpers P, et al. Prevalence and correlates of depressive symptoms in Chinese older adults: a population-based study. Int $\mathrm{J}$ Geriatr Psychiatry, 2012,27(3):305-312

5 Zhang B, Li J. Gender and marital status differences in depressive symptoms among elderly adults: the roles of family support and friend support. Aging Ment Health, 2011,15(7):844-854

6 Rudisch B, Nemeroff CB. Epidemiology of comorbid coronary artery disease and depression. Biol Psychiatry, 2003,54(3):227-240

7 Anderson RJ, Freedland KE, Clouse RE, et al. The prevalence of comorbid depression in adults with diabetes: a meta-analysis. Diabetes Care, 2001,24(6): 1069-1078

8 Matcham F, Rayner L, Steer S, et al. The prevalence of depression in rheumatoid arthritis: a systematic review and meta-analysis. Rheumatology (Oxford), 2013, 52(12):2136-2148

9 Moussavi S, Chatterji S, Verdes E, et al. Depression, chronic diseases, and decrements in health: results from the World Health Surveys. Lancet, 2007,370(9590):851858

10 Abegunde DO, Mathers CD, Adam T, et al. The burden and costs of chronic diseases in low-income and middleincome countries. Lancet, 2007,370(9603):1929-1938

11 Bisschop MI, Kriegsman DM, Deeg DJ, et al. The longitudinal relation between chronic diseases and depression in older persons in the community: the Longitudinal Aging Study Amsterdam. J Clin Epidemiol, 2004,57(2):187-194

12 Olvera RL, Fisher-Hoch SP, Williamson DE, et al. Depression in Mexican Americans with diagnosed and undiagnosed diabetes. Psychol Med, 2016,46(3):637646

13 Tong A, Wang X, Li F, et al. Risk of depressive symptoms associated with impaired glucose metabolism, newly diagnosed diabetes, and previously diagnosed diabetes: a meta-analysis of prospective cohort studies. Acta Diabetol, 2016,53(4):589-598

14 Nouwen A, Nefs G, Caramlau I, et al. Prevalence of depression in individuals with impaired glucose metabolism or undiagnosed diabetes: a systematic review and meta-analysis of the European Depression in Diabetes (EDID) Research Consortium. Diabetes Care, 2011,34(3):752-762

15 Xue J, Chen S, Bogner HR, et al. The prevalence of depressive symptoms among older patients with hypertension in rural China. Int J Geriatr Psychiatry, 2017,32(12):1411-1417

16 Kawada T. The prevalence of depression in rheumatoid arthritis: a systematic review and meta-analysis.
Rheumatology (Oxford), 2014,53(3):578

17 Palmer S, Vecchio M, Craig JC, et al. Prevalence of depression in chronic kidney disease: systematic review and meta-analysis of observational studies. Kidney Int, 2013,84(1):179-191

18 Xiao T, Qiu H, Chen Y, et al. Prevalence of anxiety and depression symptoms and their associated factors in mild COPD patients from community settings, Shanghai, China: a cross-sectional study. BMC Psychiatry, 2018,18(1):89

19 Krebber AM, Buffart LM, Kleijn G, et al. Prevalence of depression in cancer patients: a meta-analysis of diagnostic interviews and self-report instruments. Psycho-oncology, 2014,23(2):121-130

20 Chen MH, Su TP, Chen YS, et al. Higher risk of developing major depression and bipolar disorder in later life among adolescents with asthma: a nationwide prospective study. J Psychiatr Res, 2014,49:25-30

21 Fei K, Benn EK, Negron R, et al. Prevalence of Depression Among Stroke Survivors: Racial-Ethnic Differences. Stroke, 2016,47(2):512-515

22 Read JR, Sharpe L, Modini M, et al. Multimorbidity and depression: A systematic review and meta-analysis. J Affect Disord, 2017,221:36-46

23 Lewinsohn PM, Hoberman HM, Teri L, et al. An integrative theory of depression. Theoretical issues in behavior therapy. Orlando, FL: Academic Press. 1985.

24 Paunio T, Korhonen T, Hublin C, et al. Poor sleep predicts symptoms of depression and disability retirement due to depression. J Affect Disord, 2015,172:381-389

25 Zis P, Daskalaki A, Bountouni I, et al. Depression and chronic pain in the elderly: links and management challenges. Clin Interv Aging, 2017,12:709-720

26 Zhao Y, Hu Y, Smith JP, et al. Cohort profile: the China Health and Retirement Longitudinal Study (CHARLS). Int J Epidemiol, 2014,43(1):61-68

27 Song A, Liang Y, Yan Z, et al. Highly prevalent and poorly controlled cardiovascular risk factors among Chinese elderly people living in the rural community. Eur J Prev Cardiol, 2014,21(10):1267-1274

28 National Cholesterol Education Program (NCEP) Expert Panel on Detection E, and Treatment of High Blood Cholesterol in Adults (Adult Treatment Panel III). Third Report of the National Cholesterol Education Program (NCEP) Expert Panel on Detection, Evaluation, and Treatment of High Blood Cholesterol in Adults (Adult Treatment Panel III) final report. Circulation, 2002,106(25):3143-3421.

29 Association AD. Diagnosis and classification of diabetes mellitus. Diabetes Care, 2014,37 Suppl 1:S81-90

30 Marengoni A, Rizzuto D, Wang HX, et al. Patterns of chronic multimorbidity in the elderly population. J Am Geriatr Soc, 2009,57(2):225-230

31 Kriegsman DM, Penninx BW, van Eijk JT, et al. Selfreports and general practitioner information on the presence of chronic diseases in community dwelling elderly. A study on the accuracy of patients' self-reports and on determinants of inaccuracy. J Clin Epidemiol, 1996,49(12):1407-1417

32 Qin T, Liu W, Yin M, et al. Body mass index moderates the relationship between $\mathrm{C}$-reactive protein and depressive symptoms: evidence from the China Health 
and Retirement Longitudinal Study. Sci Rep, 2017,7:39 940

33 Chen HJ, Mui AC. Factorial validity of the Center for Epidemiologic Studies Depression Scale short form in older population in China. Int Psychogeriatr, 2014,26(1):49-57

34 Katz S, Ford AB, Moskowitz RW, et al. Studies of illness in the aged. The index of ADL: a standardized measure of biological and psychosocial function. JAMA, 1963,185:914-919

35 Lawton MP, Brody EM. Assessment of older people: self-maintaining and instrumental activities of daily living. Gerontologist, 1969,9(3):179-186

36 Hylands-White N, Duarte RV, Raphael JH. An overview of treatment approaches for chronic pain management. Rheumatol Int, 2017,37(1):29-42

37 Yoshida K, Lin TC, Wei M, et al. The roles of postdiagnosis accumulation of morbidities and lifestyle changes on excess total and cause-specific mortality risk in rheumatoid arthritis. Arthritis Care Res (Hoboken), 2019. doi: 10.1002/acr.24120

38 Ni Y, Tein JY, Zhang M, et al. Changes in depression among older adults in China: A latent transition analysis. J Affect Disord, 2017,209:3-9

39 Lichtman JH, Froelicher ES, Blumenthal JA, et al. Depression as a risk factor for poor prognosis among patients with acute coronary syndrome: systematic review and recommendations: a scientific statement from the American Heart Association. Circulation, 2014,129(12):1350-1369

40 Peters A, McEwen BS. Stress habituation, body shape and cardiovascular mortality. Neurosci Biobehav Rev, 2015,56:139-150

41 Mahmood S, Hassan SZ, Tabraze M, et al. Prevalence and Predictors of Depression Amongst Hypertensive Individuals in Karachi, Pakistan. Cureus, 2017,9(6):e1397

42 Badescu SV, Tataru C, Kobylinska L, et al. The association between Diabetes mellitus and Depression. J Med Life, 2016,9(2):120-125

43 Pashaki MS, Mezel JA, Mokhtari Z, et al. The prevalence of comorbid depression in patients with diabetes: A meta-analysis of observational studies. Diabetes Metab Syndr, 2019,13(6):3113-3119
44 Kim SY, Chanyang M, Oh DJ, et al. Association between depression and rheumatoid arthritis: two longitudinal follow-up studies using a national sample cohort. Rheumatology (Oxford), 2020,59(8):1889-1897

45 Besirli A, Alptekin JO, Kaymak D, et al. The Relationship Between Anxiety, Depression, Suicidal Ideation and Quality of Life in Patients with Rheumatoid Arthritis. Psychiatr Q, 2020,91(1):53-64

46 Soosova MS, Macejova Z, Zamboriova M, et al. Anxiety and depression in Slovak patients with rheumatoid arthritis. J Ment Health, 2017,26(1):21-27

47 Read JR, Sharpe L, Modini M, et al. Multimorbidity and depression: A systematic review and meta-analysis. J Affect Disord, 2017,221:36-46

48 Stubbs B, Vancampfort D, Veronese N, et al. Depression and physical health multimorbidity: primary data and country-wide meta-analysis of population data from 190 593 people across 43 low- and middle-income countries. Psychol Med, 2017,47(12):2107-2117

49 Katon W, Lin EH, Von Korff M, et al. Integrating depression and chronic disease care among patients with diabetes and/or coronary heart disease: the design of the TEAMcare study. Contemp Clin Trials, 2010,31(4):312322

50 Beck AT. The evolution of the cognitive model of depression and its neurobiological correlates. Am J Psychiatry, 2008,165(8):969-977

51 Williamson GM. Extending the activity restriction model of depressed affect: evidence from a sample of breast cancer patients. Health Psychol, 2000,19(4):339347

52 Hepgul N, Mondelli V, Pariante CM. Psychological and biological mechanisms of cytokine induced depression. Epidemiol Psichiatr Soc, 2010,19(2):98-102

53 Gaskin DJ, Richard P. The economic costs of pain in the United States. J Pain, 2012,13(8):715-724

54 Gerrits MM, van Oppen P, van Marwijk HW, et al. Pain and the onset of depressive and anxiety disorders. Pain, 2014,155(1):53-59

55 van den Akker M, van Steenkiste B, Krutwagen E, et al. Disease or no disease? Disagreement on diagnoses between self-reports and medical records of adult patients. Eur J Gen Pract, 2015,21(1):45-51

(Received May 18, 2020; accepted Aug. 3, 2020) 